\title{
Characterizing maximum residential water demand
}

\author{
S. Gato-Trinidad ${ }^{1} \&$ K. Gan ${ }^{2}$ \\ ${ }^{I}$ Faculty of Engineering and Industrial Sciences, \\ Swinburne University of Technology, Australia \\ ${ }^{2}$ Yarra Valley Water, Australia
}

\begin{abstract}
The design of water and wastewater supply systems is traditionally based on maximum water demand which is a function of multiple factors. Understanding these factors and how these affect maximum water demand will lead to the estimation of appropriate peak design factors for a more cost effective design of water and wastewater supply systems. This paper describes the maximum water demand of four separate residential suburbs in Greater Melbourne, Australia with populations ranging from 1000 to 20,774. The study involves the analysis of water consumption data recorded at five-minute intervals over one year. The effects of population and the sampling interval on the peak factor have been analysed. From a set of data collected at five-minute intervals, further data sets at $10,20,30$ and 60 minutes have been derived. New equations to estimate the peak flow demand for a small number of the population have been developed. Results also show that at five-minute intervals, a more accurate peak design factor has been estimated.

Keywords: maximum water demand, peak design factors, waste and water supply systems, Greater Melbourne, Australia.

\section{Introduction}

The maximum residential water demand is important in the design and rehabilitation of water and wastewater supply distribution systems as peak flow demand serves as the basis for sizing supply components.
\end{abstract}


Gato et al. [1] and some researchers (e.g. Tricario et al. [2], Garcia et al. [3], Buchberger and Wells [4]) have studied the diverse and complex factors influencing water consumption.

According to Tricario et al. [2], numerous relationships exist to evaluate the peak phenomenon (e.g. Babbitt [5] and Rich [6]) but these are usually with reference to residential areas with a minimum of 5000-10 000 residents. They found out that less attention is given to the case of a small number of users where the peak phenomenon is often more important if compared with the average flow requirements.

With the objective of contributing to the characterisation of water demand models, four small suburbs of varying number of residents in Greater Melbourne, Australia under the service area of Yarra Valley Water has been investigated.

The study of maximum water demand has been undertaken considering both a deterministic approach and a probabilistic approach. Several researchers as mentioned by Tricarico et al. [2] have highlighted the need to tackle flow demand with a specific probabilistic approach as a stochastic variable (e.g. Bao and Mays [7] and Gargano and Pianese [8]).

\section{Peak demand coefficient}

Water demand data collected at 5-min interval in five suburbs of Greater Melbourne, Australia over a period of one year have been analysed. These five suburbs include Box Hill, Craigieburn, Kangaroo Ground, Ringwood and Whittlesea East (Figure 1). Table 1 presents the number of residents for each of these suburbs.

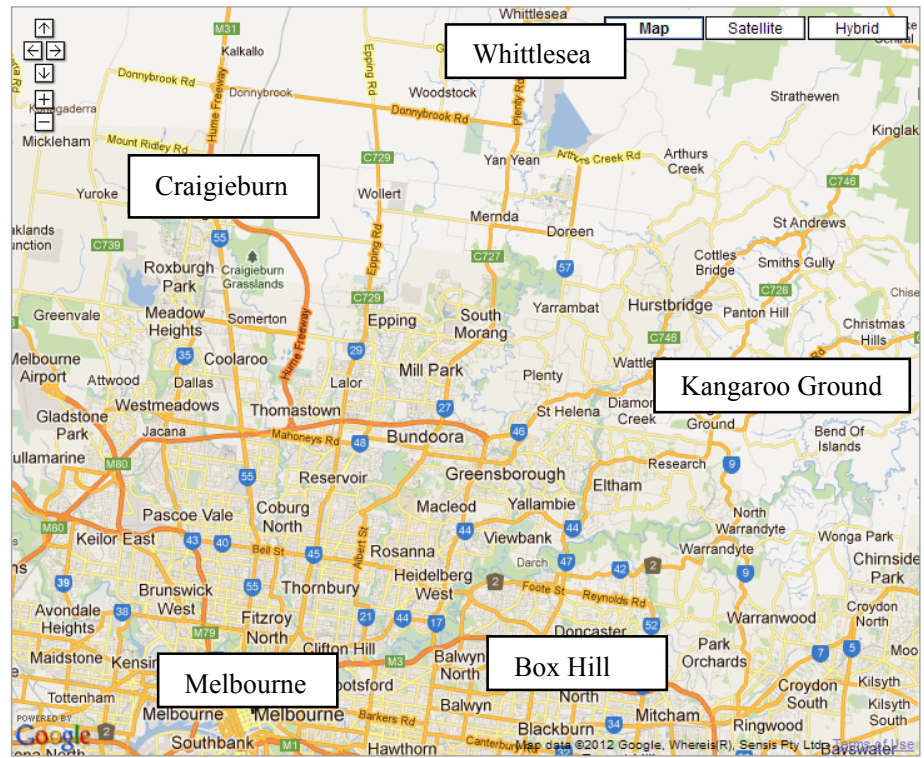

Figure 1: $\quad$ Locality map. 
Table 1: $\quad$ Melbourne suburbs and their respective populations as of 2006 (DPCD [9]).

\begin{tabular}{|c|c|}
\hline Suburb & Population \\
\hline Kangaroo Ground & 1,020 \\
\hline Whittlesea East & 3,322 \\
\hline Box Hill & 9,121 \\
\hline Craigieburn & 20,774 \\
\hline
\end{tabular}

Analysis shows that the average daily water demand does change significantly during the summer period (January till March) in Melbourne, Australia as shown in Figure 2. This could be attributed to outdoor use during the summer time. The demand pattern shown is similar to the demand pattern shown for East Doncaster, Melbourne a residential area analysed by Gato et al. [1].

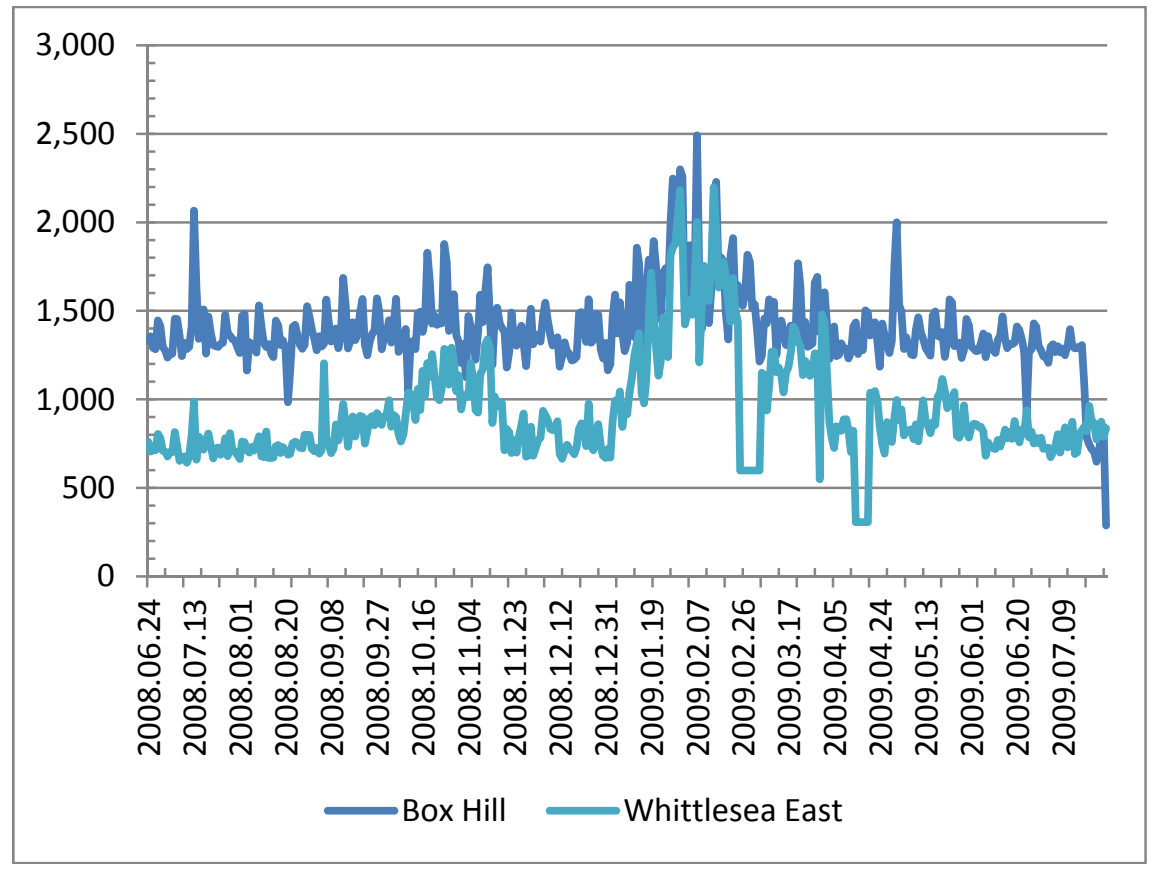

Figure 2: $\quad$ Daily water demand collected at 5-min interval (24 Jun 200827 Jul 2009), kL/day.

Figure 3 illustrates the typical daily demand pattern of suburb in Melbourne (Gato et al. [10]), in which the maximum water demand is reached early in the morning and another peak of higher intensity during summer and lower intensity in winter are present, corresponding with dinner time. 


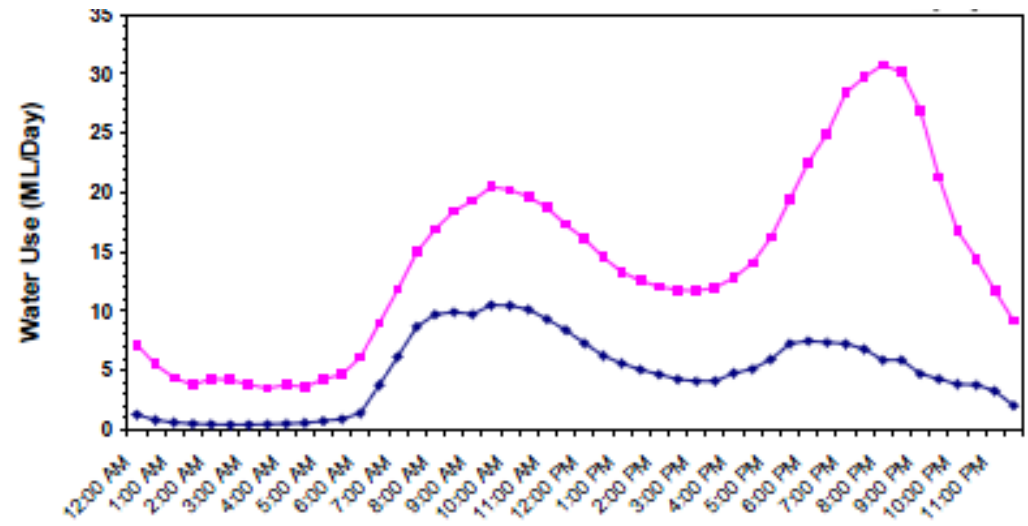

Figure 3: Typical daily demand pattern, East Doncaster, Victoria, Australia (1990-2001).

Figure 4 shows the same daily pattern of the four suburbs being analysed in this report taking into account different number of users. Results show that the daily pattern does not vary its shape during the day with the number of users supplied.

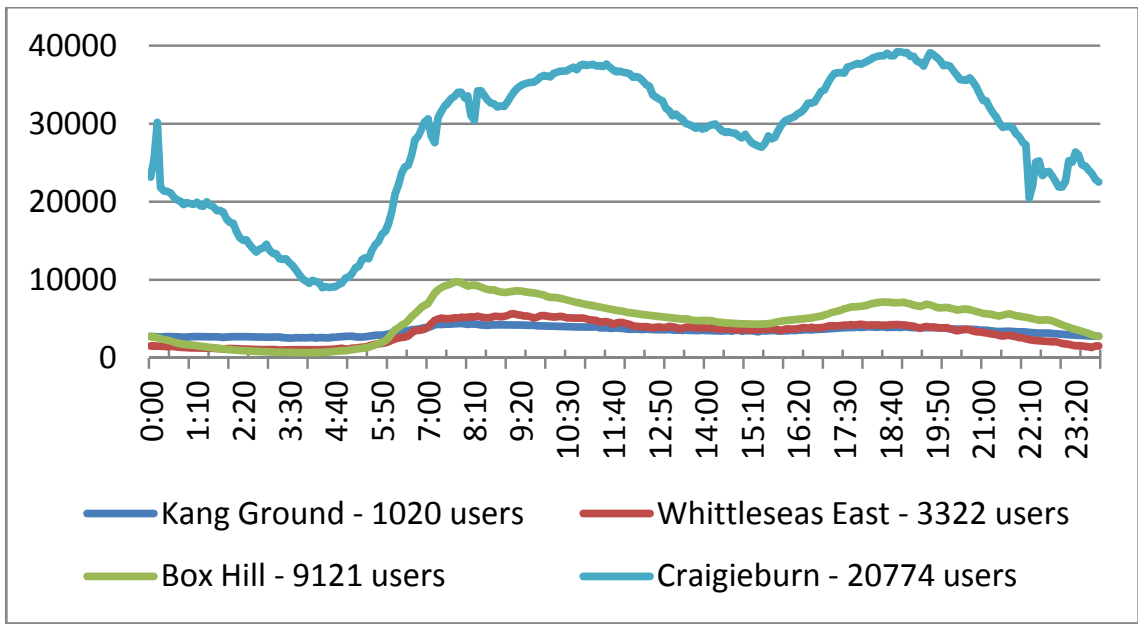

Figure 4: Typical daily demand of four suburbs with varying number of users.

A dimensionless expression of the maximum water required is thus given by the peak demand coefficient, $\mathrm{Cp}$, a ratio of the maximum flow, Qm against daily average flow, $\mathrm{Q}_{\text {ave }}$.

$$
C p=\frac{Q_{m}}{Q_{a v e}}
$$


The residential water requirement is a function of multiple factors, many of them specific to the area under consideration. Thus, there are numerous relations and tables available in the technical literature, suggesting ways for estimating the maximum water consumption (e.g. Babbitt [5] and Rich [6]). According to Tricarico et al. [2], these relations can often lead to extremely different estimates of the peak factor and usually, these do not take into consideration the random nature of the peak water demand. However, most of these express peak factors as a function of the population, $P$, as for example suggested by Babbitt [5] in the relationship:

$$
C p=5\left(\frac{P}{1000}\right)^{-0.2} \cong 20 P^{-0.2}
$$

Even if eqn. (2) originally refers to $\mathrm{Cp}$ evaluation for sewer systems, it has been widely applied in the peak drinking water studies for areas with at least 5000-10000 residents.

Table 2 which refers to some of the well-established relations and tables in the technical literature $[2,5,6,11]$ shows the $\mathrm{Cp}$ values obtained when considering smaller number of users.

Table 2: $\quad$ Peak coefficient for small residential areas.

\begin{tabular}{|c|c|c|c|c|c|}
\hline & \multicolumn{5}{|c|}{ Number of residents } \\
\hline & 100 & 250 & 750 & 1000 & 1250 \\
\hline Tricarico et al. [2] & 4.4 & 3.7 & 2.9 & 2.8 & 2.6 \\
\hline Babbit [5] & 7.9 & 6.6 & 5.3 & 5.0 & 4.8 \\
\hline Rich [6] & 7.3 & 6.3 & 5.3 & 5.0 & 4.8 \\
\hline Fair and Geyer [11] & 5.2 & 5.1 & 4.9 & 4.8 & 4.7 \\
\hline
\end{tabular}

\section{Effect of the time interval on the peak factor}

The maximum water demand is usually related to the maximum hourly demand. Eqn. (1) can be obtained as the volume of water required at the peak hour over the average, hourly flow demand volume. Assuming a time interval of one hour could result in a lower estimation of demand than is correct. According to Tricarico et al. [2], de Marinis et al. stated that taking the average may neglect major peaks that could arise during the peak hour. However, Buchberger and Li [12] argued that considering finer time scales (e.g. 1 second) would produce more information that can be justified by the quality of the hydraulic models, which operate at coarser time intervals, and could lead to over-fitting of the model. In this regard, according to Tricarico et al. [2], de Marinis et al. demonstrated that one-minute intervals can be considered to be a good compromise.

The effect of sampling resolution has been investigated in this study. From one set of flow data collected at 5 min intervals, several further data sets have been derived $\left(\Delta t=\left\{10^{\prime}, 20^{\prime} 30^{\prime}, 60^{\prime}\right\}\right)$. For each of these sets, the corresponding maximum $\mathrm{Cp}$ values $\left(\mathrm{Cp}_{\max }\right)$ have been estimated. Results obtained for the four suburbs are shown in Figure 5. It confirms previous literatures that sampling 
interval has an effect on the values of $\mathrm{Cp}$. A reduction ranging from $8 \%$ to $24 \%$ in maximum demand when considering $\Delta \mathrm{t}=1 \mathrm{~h}$, instead of $5 \mathrm{~min}$. Tricarico et al. [2] reported an underestimation of about $28 \%$ of peak demand. While Figure 5 shows that sampling interval has an effect on $\mathrm{Cp}$, it also shows that there are other factors that need to be considered in determining $\mathrm{CP}$ as reflected on different resulting equations for the four suburbs investigated in this report.

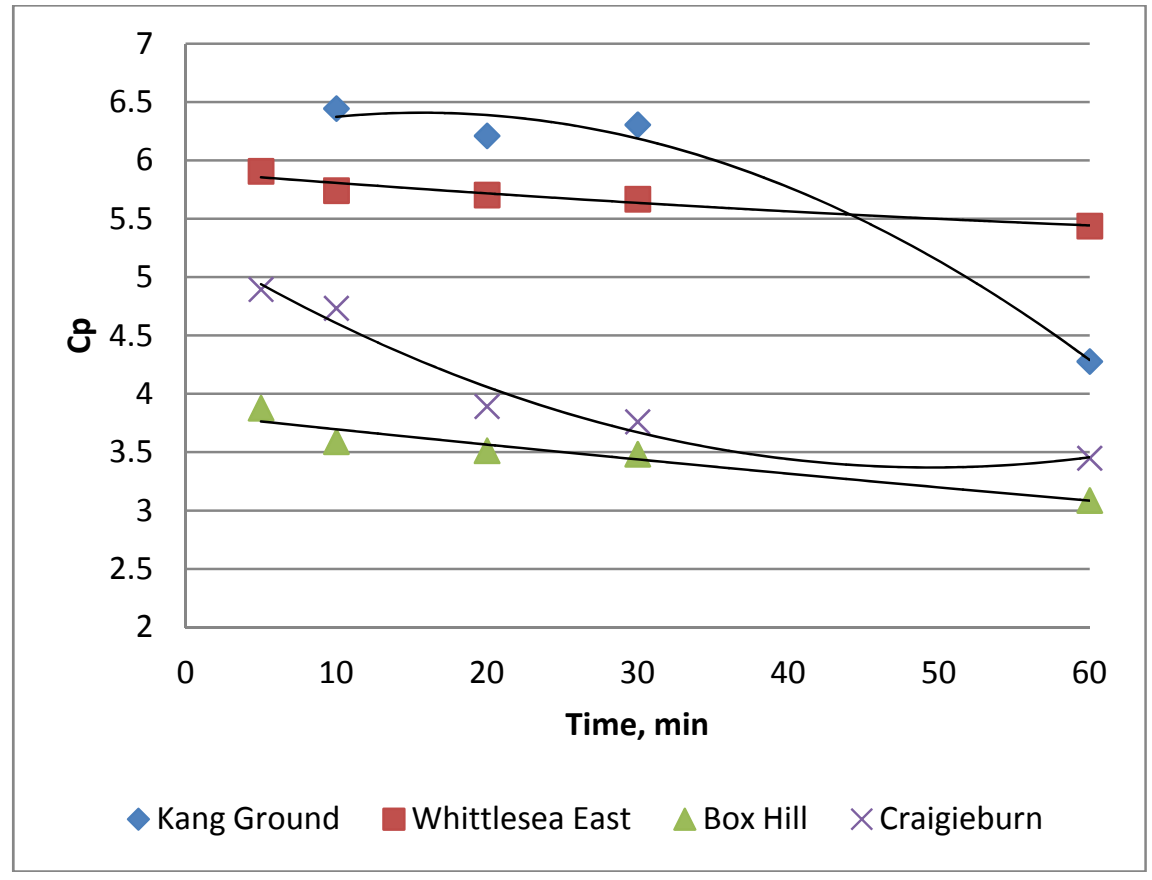

Figure 5: $\quad$ Effect of sampling interval (Time) on Cp.

\section{Peak flow data analysis}

As shown in Figure 5, other factors aside from sampling interval affect maximum water demand values and eventually $\mathrm{Cp}$. Analysis of the data has shown that maximum $\mathrm{Cp}$ can be represented as a function of a number of residents. The regression analysis undertaken on the water demand data recorded at 5-min interval resulted to the following equation with the fitted curve shown in Figure 6:

$$
\begin{gathered}
C p=29.17 P^{-0.2} \\
C p=-1.17 \ln (P)+15.66
\end{gathered}
$$

The resulting eqns. (3) and (4) thus allow the estimation of $\mathrm{Cp}$ required using a deterministic approach. The proposed eqn. (3) is similar to that by Babbitt [5], 
eqn. (2), which refers to $\mathrm{Cp}$ evaluation for sewer systems and to Tricarico et al. but with a higher coefficient. In comparison, eqn. (4) has a better fit than eqn. (3) with a coefficient of determination, $\mathrm{R}^{2}$ of $76 \%$ (against $70 \%$ ). According to Tricarico et al. [2] it is more appropriate to define confidence intervals of $\mathrm{Cp}$, with a predefined failure probability, than to use a specific value.

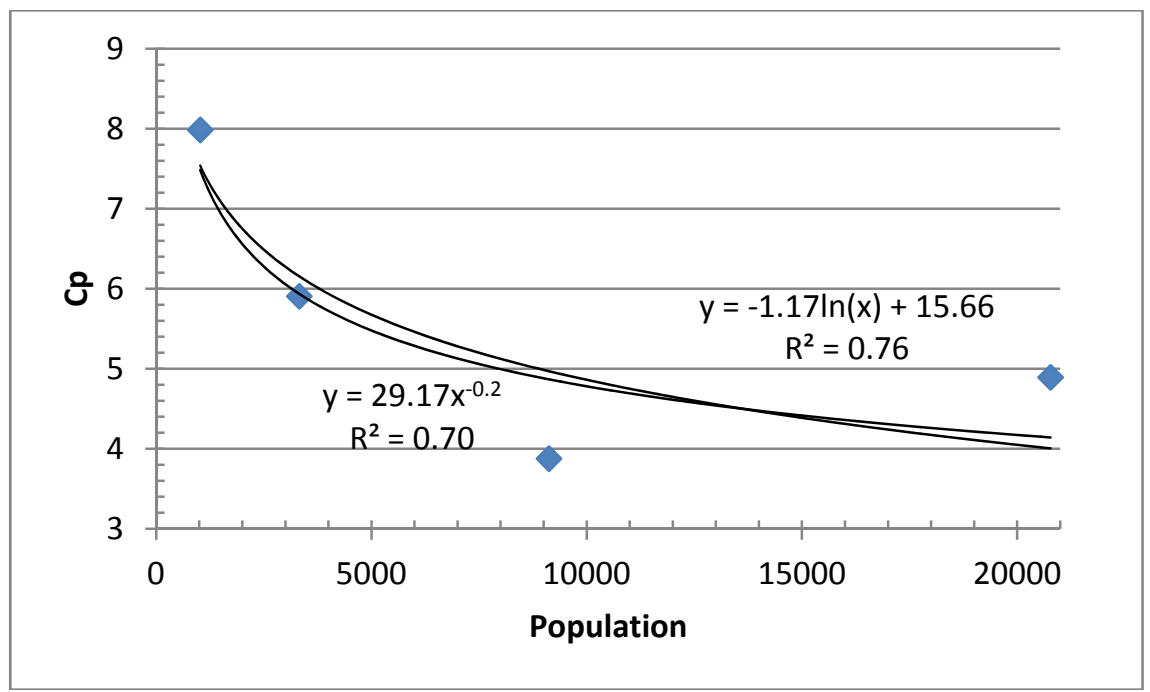

Figure 6: $\quad$ Cp against population.

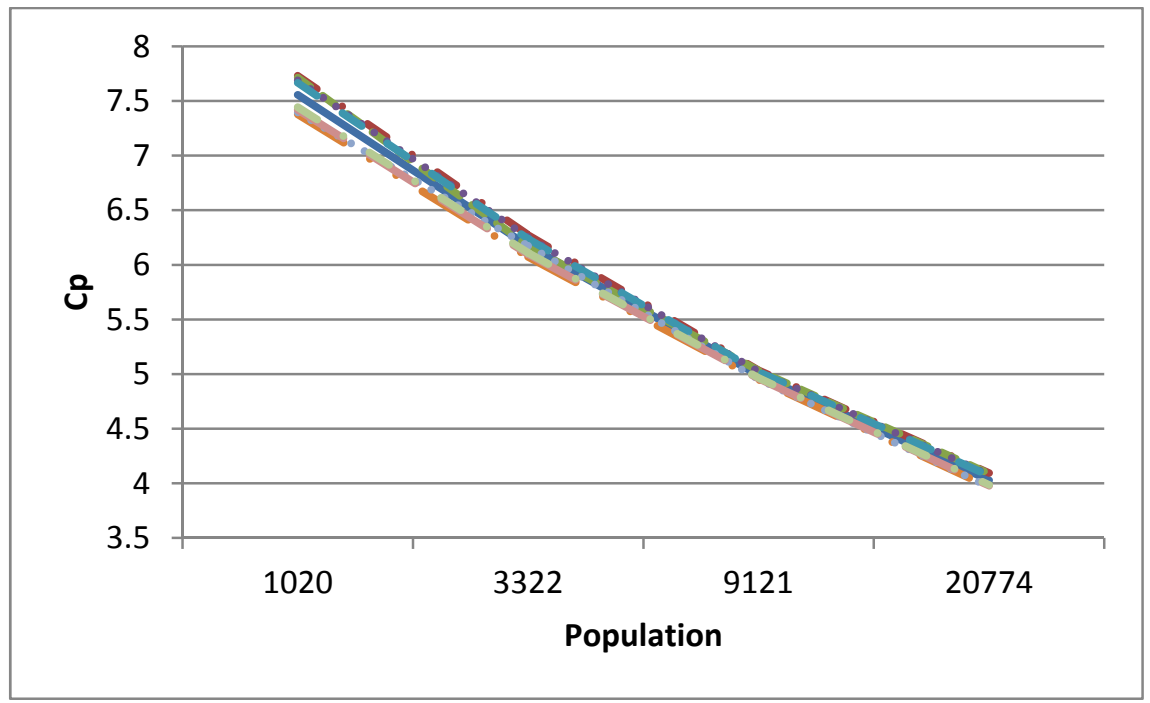

Figure 7: Average $\mathrm{Cp}$ and confidence intervals at $99 \%, 98 \%, 95 \%$ and $90 \%$. 
In Figure 7, the experimental points refer to average values of $\mathrm{Cp}$ estimation, $\hat{\mathrm{u}}_{\mathrm{Cp}}(\mathrm{P})$, and the relative confidence intervals of $90 \%, 95 \%, 98 \%$ and $99 \%$ are plotted. The $\mathrm{Cp}$ values were estimated using eqn. (4) rather than eqn. (3) due to its better fit.

The plot in Figure 7 has been prepared considering standard deviation as being variable with respect to the number of residents. Reducing the number of residents leads to an increase of the confidence intervals. This is consistent with Tricarico et al. [2] findings.

The trend of the coefficient variation, $\mathrm{CV}(\sigma / \mu)$ when varying the number of residents is shown in Figure 8. The pattern is similar to that of Tricarico et al. [2]. The corresponding equation of the curve is presented as eqn. (5)

$$
C V=-0.1 \ln (P)+1.2
$$

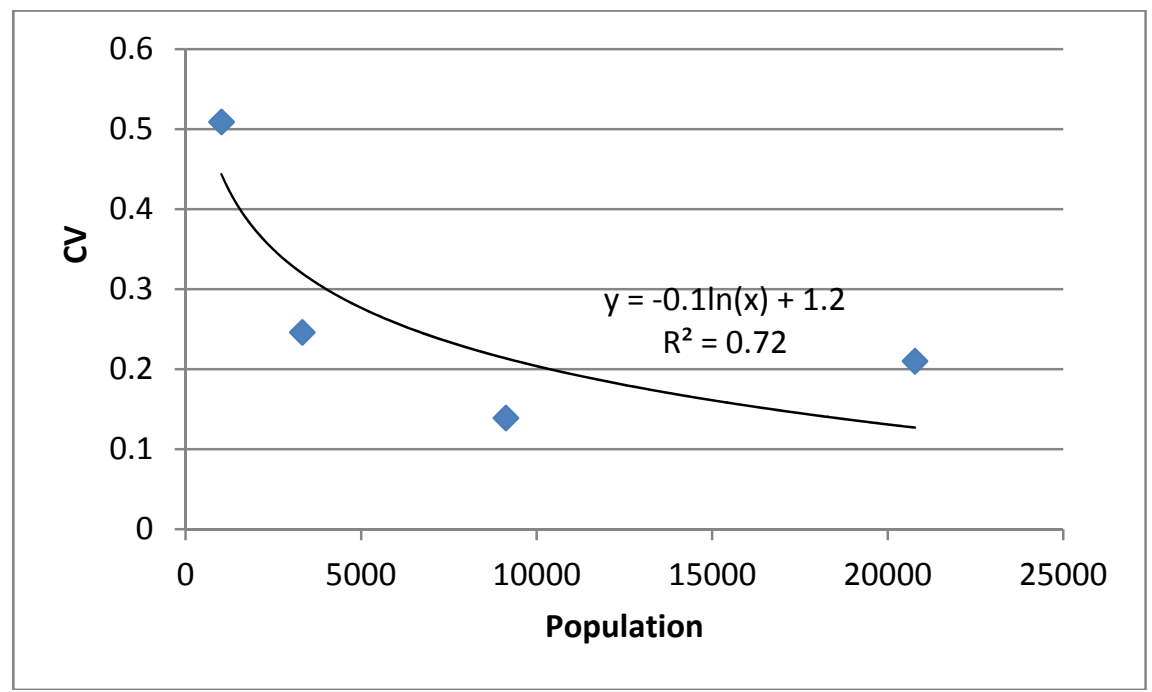

Figure 8: Variation of $\mathrm{CV}$ in relation to population.

The relationship proposed in eqn. (5) shows a good fit with the data collected from the monitoring system having a coefficient of determination, $\mathrm{R}^{2}$ of $72 \%$. $\mathrm{CV}$ increases when population $(\mathrm{P})$ decreases and vice versa. Similar to Tricarico et al. [2], when $\mathrm{P}$ increases, the $\mathrm{CV}$, based on eqn. (5), tends to 0.1 - the value largely used in the literature for large networks (e.g. Kapelan et al. [13] and Babayan et al. [14]). It is advisable that more water supply distribution zones or areas be investigated to confirm this finding.

Table 3 shows the maximum peak demand coefficient (from the deterministic approach) and the upper bounds of confidence intervals, obtained for different confidence levels (from the probabilistic approach). Comparing, for the same number of users, the results shown in Table 3 are higher than with the corresponding peak demand coefficients reported in Table 2. Such higher values are due to the timing interval of 5-min as compared to hourly peak with the exception of Tricarico et al. [2] which are based on a one-minute interval. 
Table 3: $\quad$ Peak demand coefficient, $\mathrm{Cp}$.

\begin{tabular}{|c|c|c|c|c|c|}
\hline & & \multicolumn{4}{|c|}{ Number of inhabitants } \\
\hline & & 1020 & 3322 & 9121 & 20774 \\
\hline Deterministic approach & & 7.55 & 6.17 & 4.99 & 4.03 \\
\hline Probabilistic approach & $90 \%$ & 7.67 & 6.24 & 5.02 & 4.07 \\
\hline & $95 \%$ & 7.69 & 6.25 & 5.02 & 4.08 \\
\hline & $98 \%$ & 7.71 & 6.17 & 5.03 & 4.09 \\
\hline & $99 \%$ & 7.31 & 6.27 & 5.04 & 4.09 \\
\hline
\end{tabular}

\section{Conclusions and recommendation}

An effective design of a water supply distribution network requires a better knowledge of the maximum water demand and the peak demand coefficient, $\mathrm{Cp}$.

Based on the analysis of the water demand data monitored at 5-min interval in four suburbs of Greater Melbourne, Australia, it can be concluded that:

1. A more accurate calculation of $\mathrm{Cp}$ can be achieved at 5-min interval than higher timing intervals. The pattern of $\mathrm{Cp}$ is similar to previous studies; however, the values are higher due to sampling interval differences.

2. As population increases, $\mathrm{Cp}$ decreases as well as the coefficient of variation, $\mathrm{CV}$. This confirms previous studies conducted overseas.

3. It is therefore, recommended that other suburbs in Melbourne, Australia be investigated to confirm findings and enable generalisations of the results.

\section{Acknowledgement}

Yarra Valley Water one of the three Melbourne Metropolitan water authorities in Australia is hereby acknowledged for providing water demand data used in this report.

\section{References}

[1] Gato, S., Jayasuriya, N., \& Roberts, P., Forecasting residential water demand: case study, Journal of Water Resource Planning and Management, ASCE, 133(4), pp. 309-319, 2007.

[2] Tricarico, C., de Marinis, G., Gargano, R., \& Leopardi, A., Peak residential water demand. Proc. of the Institution of Civil Engineers, Water Management 160, Issue WM2, pp. 115-121, 2007.

[3] Garcia, V. J., Garcia-Bartual, R., Cabrera, E., Arregui, F. \& Garcia-Serra, J., Stochastic model to evaluate residential water demands. Journal of Water Resource Planning and Management, ASCE, 130(5), pp. 386-394, 2004. 
[4] Buchberger, S. G. \& Wells, G. J., Intensity, duration and frequency of residential water demands. Journal of Water Resource Planning and Management, ASCE, 122(1), pp. 11-19, 1996.

[5] Babbitt, H. E., Sewerage and Sewage Treatment, $3^{\text {rd }}$ edn., Wiley: New York, pp. 28-33, 1928.

[6] Rich, L. G., Low Maintenance Mechanically Simple Wastewater Treatment Systems. McGraw-Hill: New York, 1980.

[7] Bao, Y. \& Mays, L. W., Model for water distribution system reliability. Journal of Hydraulic Engineering, ASCE, 116(9), pp. 1119-1137, 1990.

[8] Gargano, R., \& Pianese, D., Reliability as a tool for hydraulic network planning. Journal of Water Resource Planning and Management, ASCE, 126(5), pp. 354-364, 2000.

[9] Department of Planning and Community Development (DPCD) Web Site. Suburbs in time - Melbourne suburbs, Australia, http://www.dpcd.vic.gov.au/home/publications-and-research/urban-andregional-research/Census-2011/suburbs-in-time/melbourne-suburbs

[10] Gato, S., Jayasuriya, N., Roberts, P. \& Hadgraft, R., Understanding residential water use. ENVIRO 2004, Sydney, Australia, 2004.

[11] Fair, J. C., \& Geyer, J. C., Water Supply and Waste-water Disposal, Wiley: New York, 1954.

[12] Buchberger, S. G. \& Li, Z., Effect of time scale on PRP random flows in pipe network. Proceedings of the World Water and Environmental Resources Congress, Critical Transitions in Water and Environmental Resources Management, ASCE-EWRI, Salt Lake City, USA, 2004.

[13] Kapelan, Z., Savic, D. A., \& Walters, G. A., A multiobjective approach to rehabilitation of water distribution networks under uncertainty. Proc. of the $6^{\text {th }}$ International Symposium on Systems Analysis and Integration Assessment, Watermatex IWA, Beijing, China, 2004.

[14] Babayan, A. V., Kapelan, Z., Savic, D. A., \& Walters, G. A., Least cost design of water distribution network under demand uncertainty. Journal of Water Resource Planning and Management, ASCE, 131(5), pp. 375-382, 2005. 